\title{
Nick Park's Ambivalent Heroes: Technology in Wallace and Gromit
}

\author{
Susan C. W. Abbotson
}

\begin{abstract}
A close analysis of the contradictory technological imagery which runs through the British director, Nick Park's series of Wallace and Gromit short animated films - $A$ Grand Day Out (1989), The Wrong Trousers (1993) and $A$ Close Shave (1995) - shows how Park allows his protagonists, Wallace and Gromit, to become subverted and corrupted by the technological forces they attempt to master. This serves to make their victories decidedly suspect, and asks the audience to question their apparent status as 'heroes'. Both 'villains' and 'heroes' in the Wallace and Gromit series have close ties to technological forces, but the relationship they hold is an uneasy one, at best. While Park depicts Wallace and Gromit, who seem to be the films' heroes, using technology for comic relief and personal fun, he shows the villainsthe moon-machine, Preston, and Feathers McGrawusing it to exert control and for personal gain. Why is it, then, that Wallace and Gromit end up in control and with the most cash?
\end{abstract}

Part of the films' feeling of ambivalence may arise from their evident development for a dual audience. When shown on television, children embrace the cartoonish characters and swiftly moving plot, while parents appreciate the references to other shows, cinematic techniques with which they grew up, and parodies of various cultural icons. In Britain, the very idea of children's television has long presupposed that a parent may be watching alongside the child, hence the title of the popular BBC television series pioneered in the 1950 s by Freda Lingstrom, Watch with Mother, with its puppet tales of Andy Pandy, Teddy and Looby-Loo (which followed the earlier BBC radio show, Listen With Mother). Later popular children's shows such as The Magic Roundabout (first broadcast in 1965), or Captain Pugwash (first broadcast in 1957), attempted to maintain adult interest alongside the child's with surreptitious wordplay, topical references, and cultural jokes (apparently above the child's head). Wallace and Gromit continues in this vein, although apparently made for children with its cute claymation figures (a natural extension of Aardman Animation's Morph, who has featured in various children's television shows since his first appearance with Tony Hart on Vision On in 1977), the shorts are filled with nostalgic film and television references, with which the child viewer is not nearly as familiar as the parent.

Films and television series of the past, especially those for children, are filled with such formulaic features as the hero and his sidekick; chase sequences to round off endings; displays of newspaper headlines to advance plots; and the accident prone, comic yet lovable, working class hero. Park is openly derivative, creating almost a pastiche of such techniques, while being simultaneously innovative in the way he treats such cinematographic clichés. In a sense, he 'signifies' on previous formulas, by not repeating them so much as adopting and changing them to create different effects, while still recalling the original. In this way, he remains firmly in control, and able to convey a subtly subversive message about technology, while still strongly engaging his audience with the films' sense of familiarity.

Park's playing with our expectations in his films serves a number of purposes. Besides invoking the audience's feelings of nostalgia for earlier films and times, it also creates a lot of humour, and raises some interesting questions. While the Lone Ranger had his Tonto, Batman his Robin, Yogi Bear his Boo-Boo, and Dr. Who a whole variety of sidekicks - Wallace has his Gromit. In varying degrees the sidekick, though competent, has historically been shown as inferior to the 'master', portrayed as a 'child' who is still learning from the more knowledgeable 'adult' (clearly a controversial issue these days in those cases where the sidekick is from an ethnic minority). However, in the topsy-turvy world of Nick Park, and in the case of Wallace and Gromit, Gromit is depicted as both mentally and technically superior to Wallace. Ironically, Park shows a dog as the more efficient and sensitive 'person', to show just how dehumanized the man, Wallace, is in contrast. The Wrong Trousers ends with a classic train-chase sequence, long the staple of numerous westerns, only here it becomes a model train. This serves to diminish the technology lying behind the train itself, presenting it as only useful when it remains small and within man's control. Park's newspapers are filled with jokes and references to his own previous work, so they as often turn our attention to the past rather than what happens next, and while 'Wallace the Windows' becomes the latest in a long line of lovable, working class

Papers 10: 12000 
heroes, we are eventually led to question his heroic status.

Perhaps it is Park's own sense of nostalgia for a less technologically driven age, that makes him portray technology in his films as something to beware. He clearly has a strong distrust of technology, and though Wallace and Gromit are always depicted as "winning the day' against the technology of the various evil forces who threaten them and their friends, he asks us to be wary of not only what they win, but also how they win. By exploring the ways in which Park introduces technology and machinery related activities within these films, we learn something of our contemporary culture's ambivalence towards the technological, and also the amoralistic values and materialism to which technology seems inextricably linked. As sociologist Melvin Rader had already noted by 1948 , 'Modern technology and its giant spawn, industrialism, have so atomized human relations... so externalized human contacts, so entangled human nature in a net of technical functions' that people no longer treat each other as people (p.505), and matters have only worsened fifty years on. To overuse machines dampens the soul of Park's characters, and leads them to dehumanize others by thinking only in terms of money, things, and the self, rather than considering others.

The image of the machine and modern technology as endangering humanity have long been pictured in films, from Charlie Chaplin's Modern Times (1936), in which the unwary worker gets sucked into the cogs of the machine, through such technophobic epics as The Terminator series, in which technology is depicted as taking over the world and trying to exterminate the inefficient humans, to the recent children's animated film, The Brave Little Toaster (1988), in which the modern appliances are depicted as cold, scheming demons next to the cute, old-fashioned toaster and his friends, whose only wish is to serve their master. Like The Brave Little Toaster, the Wallace and Gromit shorts do not reject technology outright, but suggest that there is a line between machines that serve mankind, and machines which are allowed to dominate; it is a thin line, which at times Wallace and Gromit appear guilty of crossing, as they strive to defeat the villains against whom they are matched.
The villains of each film - the moon-machine in Grand Day, Preston in Close Shave, and Feathers McGraw in Wrong Trousers - have a lot in common. Each is presented as a sinister figure, often shown in low-angle shots to seem more threatening, with sometimes only their dark shadow on screen. Their movements are frequently accompanied by unsettling music, and they have either no eyes (as in the case of the machine), or very tiny eyes (in marked contrast to the large, innocent eyes of Wallace and Gromit), allowing us no window through which to see their souls (implying, perhaps, that they have none). Most importantly, Parks never allows any of them to speak, and their silence is damning; we must judge them by their actions alone, which seem to show a single-minded pursuit of personal gain - be it the need to ski, to thrive in business, or to steal a huge diamond. In each, the desire for financial gain seems uppermost - with the moon-machine only coming to life when he is given money. Preston first rustles sheep for their wool, but then escalates to killing them for their meat to make dog food, all for the sake of profit. Feathers is a well-known thief who on being released from jail, immediately begins planning his next heist.

Technology plays a central role in allowing the villains to pursue their goals and betrays their strong mutual desire for control. In Grand Day, the moon-machine guards its territory and is displeased at the very presence of Wallace and Gromit on the moon's surface; acting as a mechanized policing machine, it attempts to strong-arm the easygoing couple to its will. In Close Shave, Preston steals Wallace's machine designs to mechanize his nefarious operations, and asserts control over both his mistress and the new intruders by removing Gromit from the picture with a clever frame-up, and later assigning his mistress to the next batch of dog meat. In Wrong Trousers, Feathers quite literally wrests control from Wallace by removing the control buttons from the Techno-trousers and making them work from a remote unit which he uses to get Wallace to steal the diamond for him.

While the villains use technology to maintain strict order, or to line their own pockets, the technology of Wallace and Gromit seems to run counter to this by its very playfulness. Indeed, Wallace's inventions seem to be 
purely for fun as they mostly perform unnecessary tasks, serving no useful function beyond spicing up the mundane routine of their lives as the town's window-cleaners. Even their rocket ship, designed for the sole purpose of getting them to the moon to replenish their stock of cheese, seems playful, with its toaster feature, and interior living room decor complete with lamps, wallpaper, pictures on the wall, and a cosy armchair. Just like a child's firework rocket on the popular British festivity, bonfire night, they even have to light the fuse to set it going.

In Close Shave this childish aspect of the inventions becomes even more pronounced, with Wallace's bizarre contraptions to get him out of bed, dressed, and fed, and then take him to his motorbike in the style of the well. known 1960s children's TV series, Thunderbirds. Both the porridge and suds gun (the same invention, though used in two different comical situations), recall the creampie guns in the children's film Bugsy Malone, and the Wash-o-matic looks like something Rube Goldberg might have designed. In The Wrong Trousers, the ways in which the trousers are used marks the character of the user: while Feathers uses them in a daring fashion to steal a diamond, Wallace has them take the dog for a walk, and Gromit to paint the ceiling of his new bedroom: simple tasks for simple, child-like folk. The couple even have a toy train zipping around their house.

In contrast to the efficient, single-minded villains, Wallace, especially, is portrayed as rather clumsy and easily distracted. When he goes to design a rocket ship he starts to play tic-tac-toe, and he forgets important details, such as taking the cheese crackers and lighting the rocket's fuse when they are about to leave. In Close Shave, instead of cleaning windows he flirts with the shop owner, and then walks right into her glass door by mistake. He also gets trampled on by sheep, more than once, and stuck in a tiny sweater. He behaves just like those accident-prone, lovable film characters continuously played by actors such as Norman Wisdom or George Formby, and like them, despite the numerous pratfalls, never seems to get seriously injured. In Wrong Trousers, he even forgets his best friend, Gromit, and is very easily tricked by Feathers. $\mathrm{He}$ is shown in numerous undignified poses, from hanging from the ceiling in striped pyjama bottoms and a bike helmet, to sitting in a vegetable rack in his underwear with a net on his head. How could such a sweet idiot be seen in any kind of negative light? Gromit appears to be a little more wily, and less easily distracted, but he is just as prone to pratfalls and ridiculous poses.

With their goofy smiles, comical ears, and friendly, homespun appearance there can surely be nothing threatening about Wallace or Gromit. Their pursuit is not cash or control, but of happiness: they go to the moon for a lark, wash windows as an artistic challenge, and Wallace spends all the available cash they have on the Technotrousers, which he hopes will be a fun birthday present for his friend, Gromit. They are somewhat reminiscent of the fools or simpleton figures in folk tales, such as $\mathrm{Mr}$. Vinegar or Hans in Luck, who bumble along, and by an apparently lucky chance end up with the wealth and/or fame. Wallace and Gromit seem to drift contentedly through life, letting it take them along in its flow rather than trying to control anything.

However, one could see their lack of control as dangerous rather than endearing. They may treat technology as a toy, but it is a powerful toy which has a way of frequently turning against them (often through their own incompetence) and could endanger others in the process. Their relationship with technology is far edgier than it may first appear. While their rocket ship allows them to go pillaging on the moon, they nearly blow it apart on a number of occasions by forgetting to light the ignition fuse and by leaving on the hand brake. Gromit gets badly spun around when he loses control of a drill he is using, and it is Wallace who twice deposits a coin to get the moon-machine working, when its every gesture towards them is certainly harmful.

In Close Shave we see most of Wallace's gadgets go wrong: getting him out of bed too quickly and the wrong way round, both he and Gromit get splatted by the porridge/suds gun; they lose control of the Wash-0-matic when they put Sean into it; and it is clear that Gromit, too, has had a bad experience with this machine. Preston uses Wallace's designs of the wash-0-matic to create something even more sinister, and it is Wallace pressing the wrong button which gets him, the sheep and Wendolene onto the 
conveyor belt for the mincing machine. Their progress becomes an almost overwhelming catalogue of incompetence and technological let-down, which gets progressively worse in The Wrong Trousers. Here, the trousers go so badly wrong that they start a chain of events that force Gromit to leave home, and then lead Wallace into becoming a jewel thief. We are warned about the unreliability of technology from the start, when Gromit's electronic birthday card runs down. The gadget to get Wallace out of bed now turns against both of them, by depositing Wallace into the trouser trap, and by tangling up Gromit when he goes to the aid of his friend.

For all of their innocent appearance, their stupidity, irresponsibility, and faith in technology may make Wallace and Gromit more dangerous than the supposed villains. in Grand Day. Wallace's descent into the dark cellar can be seen as rather sinister, with Wallace caught in a spotlight for a moment as if he were an escaping criminal. The rocket they build is shown at a menacing low angle which dwarfs its builders, and we see its destructive potential as it destroys a garden gnome on take-off. Indeed, their mission is one of utter destruction: they intend to devour the moon! The poor moon-machine is all that exists to prevent their evil plan.

Despite its mechanical appearance, the moon-machine has very human emotions, and all it desires is to have fun. just like Wallace and Gromit. But they do not help; instead they litter and pollute the machine's home. The machine cleans up after their mess, trying to repair the damage they cause, and when it tries to arrest them to prevent any further misuse of the moon, they take away its policeman's truncheon (the badge of true authority) and leave it behind when it tries to hitch a ride to go skiing on Earth. But the moon-machine is resilient; despite its disappointment it refuses to give up its dream, unlike Wallace and Gromit who leave totally dissatisfied with their cheese-seeking mission. The machine crafts skis for itself out of remnants from the rocket ship and manages to ski on the moon's surface, even being so forgiving as to happily wave at the retreating cheese-bandits in the pleasure of having achieved its goal (no thanks to their help).

In Close Shave, we see Wallace allowing his love of
Wendolene to blind him to the truth of what is going on around him. This results in his best friend being sent to jail, and he himself providing the blueprints for Preston's unpleasant machines. The disarray, as Wallace's home becomes filled with sheep, indicates the chaos that has been unleashed by their interference. One wonders, if it had not been for this interference, if Preston would have remained happy just using the sheep for wool. Preston is, after all, only protecting his mistress, Wendolene, as he has been programmed to do. During a wool shortage. he ensures that her wool shop business, and only livelihood, does not fail, by ensuring she has a continual supply of wool. In the picture of him with his master and creator, Wendolene's father, he looks perfectly amiable, and nothing like the damaged creature we see at the close.

What becomes increasingly noticeable in the progression of these films is the increasing dehumanization that is taking place just off centre stage. There is a choice moment in Grand Day which illustrates what will become a growing propensity, where Wallace dehumanizes Gromit by making him replace a wooden sawhorse. At the close of Close Shave, Wallace takes away all of Preston's character when he rebuilds him, and matters speedily escalate in Wrong Trousers. Here, images of technology encroaching on natural life become increasingly obvious, from the flying rockets replacing the flying ducks on the wall at the start, to the Techno-trousers imposing an alien will on both Gromit and Wallace. When Wallace first sends Gromit out for a walk with the trousers in control we should recognize that this will become a problem. Gromit tries to fool the trousers by replacing himself with a toy dog on a trolley, but by the end of the walk, the trousers have replaced the toy dog with Gromit, who is now on a trolley rather than being allowed to walk on his own legs. Later the trousers take over Wallace's will as they run him all over town, and then take him to steal the diamond. It is perhaps a case of those who live by technology may just die by technology.

Gromit's bone wallpaper may seem like a natural design for a dog, but it is also a symbol of thievery and death, which stands in contrast to the more vital image of the fish with which Feathers tries to replace it. It seems significant that the diamond which Feathers is after is being kept in 
a room full of death, with mummies, skeletons, and the remains of dinosaurs, thus connecting the concept of wealth to that of death. It is a living death Feathers cannot escape; he ends up being sent to the zoo where he will be stripped of any remaining dignity. However, it is Wallace and Gromit who end up with the wealth rather than the penguin, but as we leave them counting their cash, thinking that they have safely disposed of the troublesome trousers, Park shows those same trousers taking off by themselves into the sunset as the screen fades to black. Who knows what dangers they have unleashed upon the world?

Hierarchies of technology certainly exist in each of the Wallace and Gromit films. While Grand Day seems to privilege Wallace and Gromit's rocket over the moonmachine, Close Shave privileges the inventions of Wallace over those of Wendolene's father, and Wrong Trousers sets up Wallace and Gromit against the evil Feathers McGraw. However, the question we need to ask is, who is shown, finally, to have the moral ascendancy, and how can we read Wallace and Gromit's victories? In Grand Day, the supposedly humanitarian couple, having pillaged the moon for a basket of cheese, abscond without a thought for the creature they have robbed and left behind. In Close Shave, the lady is ditched because of her squeamishness regarding cheese, and her companion$\operatorname{dog}$ (who has kept her in business in a declining market) is altered, by Wallace, into an ineffective and pathetic parody of his former identity. In Wrong Trousers, Feathers McGraw, the penguin, ends up in that horror of horrors, the zoo, so deftly exposed and demonized in Park's earlier short, Creature Comforts, and Wallace and Gromit become the capitalists, last seen counting their illgotten gains! From this perspective Wallace and Gromit can be seen, in many ways, as being subverted by the very forces they seek to conquer, and it may be, finally, the villains within these films with whom our sympathies should lie.

\section{REFERENCES}

The Brave Little Toaster (1988) Dir. Jerry Rees. Prod. Hyperion/Kushner-Locke, Walt Disney.

Bugsy Malone (1976) Dir. Alan Parker. Prods. David
Putnam and Allan Marshall, Rank.

Captain Pugwash (1957) BBC. England.

A Close Shave [1995] (1996) Dir. Nick Park. Prod. Aardman Animations, Videocassette, BBC Worldwide.

'Creature Comforts' [1989] (1997) Dir. Nick Park. Prod. Aardman Animations. In Creature Comforts. Videocassette, FOX/CBS.

A Grand Day Out [1989] (1995) Dir. Nick Park. Prod. Aardman Animations, Videocassette, BBC Worldwide.

The Magic Roundabout (1965) By Serge Danot. Adapt. Eric Thompson. BBC, England.

Modern Times (1936) Dir. Charlie Chaplin. Prod. Charlie Chaplin.

Rader, Melvin (1948) 'Technology and the mandates of survival', Scientific Monthly 66: 502-13.

The Terminator (1984) Dir. James Cameron. Prod. Pacific Western, Orion.

Thunderbirds (1966) Prods. Gerry Anderson and Sylvia Anderson, ITC television Corporation.

Vision On (1977) Perf. Tony Hart. BBC, England.

Watch With Mother (1952-1979) By Maria Bird. Prod. Freda Lingstrom, BBC, England.

The Wrong Trousers [1993](1995) Dir. Nick Park. Prod. Aardman Animations, Videocassette, BBC Worldwide.

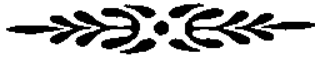

\section{BIOGRAPHICAL NOTE}

Susan Abbotson gained her PhD from the University of Connecticut, and currently teaches children's literature at Rhode Island College. Her latest book, The Student Companion to Arthur Miller comes out next month from Greenwood Press. She has published articles on drama and children's literature, as well as African-American and Jewish-American literature.

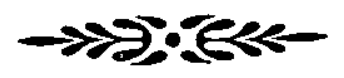

